\title{
COVID-19: Zinc and Angiotensin-Converting Enzyme 2 (ACE2) Deficiencies as Determinants of Risk and Severity of Disease: A Narrative Review
}

Miklos P. Salgo (D)

Received: April 1, 2021 / Accepted: June 5, 2021 / Published online: July 11, 2021

(c) The Author(s) 2021

\section{ABSTRACT}

A growing body of evidence supports the premise that deficiencies of zinc and angiotensinconverting enzyme 2 (ACE2, a zinc enzyme) determine severity of coronavirus disease 2019 (COVID-19). ACE2 is part of the renin-angiotensin system (RAS) and acts as a feedback control system moderating blood pressure, keeping blood pressure within normal limits. For a virus to infect a person, the virus has to get inside the person's cells. The virus that causes COVID-19 uses ACE2 to get into the cell. Think of this like an invader from outer space attacking your car by getting in through your cruise control; the RAS is like the cruise control of your car. What happens next depends on how robust your cruise control is. If your cruise control is young and healthy perhaps very little happens; your car may slow down or speed up a bit. But if your cruise control is in poor condition the attack might disrupt the entire speed control system; your car may brake suddenly or speed out of control and crash. Feedback control systems (natural or man-made) are designed to keep dynamic systems in control, but under

Miklos P. Salgo: Independent researcher, infectious diseases. No current affiliation (retired).

M. P. Salgo $(\bowtie)$

Hillsborough, CA, USA

e-mail: miklossalgo@aol.com certain situations can drive the system completely out of control. The RAS is composed of two feedback loops: the ACE loop provides amplification, increasing pro-inflammatory cytokines and blood pressure; the ACE2 loop provides fine control and mitigates the vasoconstrictive, pro-inflammatory, and thrombotic actions of the ACE loop. Usually, there is balance, but in the setting of COVID-19, underlying deficiencies of zinc and ACE2 can lead to an imbalance. Exacerbated by the severe downregulation of ACE2 seen with viral entry, a "tipping point" is reached with loss of control of the RAS system resulting in increased angiotensin II (Ang II) causing downstream vasoconstriction, inflammation, and thromboses. These, in turn, lead to complications often seen in "severe COVID-19" such as acute respiratory distress syndrome (ARDS) or cytokine storm, often seen in high-risk patients in the second week of illness. This model suggests that supplemental zinc could replenish zinc in ACE2, stabilize the ACE2 axis, and prevent disruption of the RAS. This would prevent the vasoconstrictive, inflammatory, and thrombotic actions of Ang II, thus preventing the severe COVID-19 complications which cause the high morbidity and mortality seen in high-risk patients with underlying zinc deficiency. Zinc supplements are available, easy to use, and relatively safe. Randomized clinical trials are needed to confirm safety and efficacy of zinc supplementation to decrease severity of and 
morality from COVID-19 in high-risk patients. Since replenishment of zinc and active ACE2 in patients in whom these are deficient may take weeks, supplementation in high-risk populations prior to COVID infection may be required. Such supplementation should not replace vaccination but may be useful in populations for whom vaccination is not available or for populations exposed to viral variants to which available vaccines have insufficient coverage.

Keywords: Angiotensin-converting enzyme 2 (ACE2); COVID-19; Future treatments; Narrative review; Pathophysiology; Renin-angiotensin system (RAS); SARS-CoV-2; Zinc; Zinc deficiency

\section{Key Summary Points}

Angiotensin-converting enzyme 2 (ACE2)

is a key component of the renin-angiotensin system (RAS)

SARS-CoV-2 virus uses ACE2 for cell entry

These two facts can explain high-risk populations, symptoms, and clinical progression

High-risk groups likely to be zinc or ACE2 deficient

ACE2 and zinc deficiency leads to imbalance of the RAS, predominance of ACE adverse axis. Exacerbated by downregulation of ACE2 with viral entry leads to Ang II-mediated increase in vasoconstrictive, inflammatory, and thrombotic actions leading to severe sequelae (e.g., ARDS, cytokine storm)

Randomized clinical trials needed to confirm efficacy and safety of zinc supplementation to decrease severe sequelae and mortality of COVID-19, especially in those unable or unwilling to access vaccination or those who may be at increased risk from viral variants that are insufficiently covered by available vaccines.

\section{INTRODUCTION}

This is a narrative review focusing on the role of zinc and the zinc enzyme angiotensin-converting enzyme 2 (ACE2) in the renin-angiotensin system (RAS). ACE2 is the portal to cell entry for severe acute respiratory syndrome coronavirus 2 (SARS-CoV-2), thus linking the RAS to viral infection. Review of the literature has revealed an emerging consistent narrative that explains much that we see in risk factors, symptoms, and course of disease in COVID-19. The conceptual framework encompassing this narrative points to a pathophysiologic mechanism of disease. The true value of this approach will be if therapeutic interventions based on this framework are safe and effective in decreasing severity and mortality of COVID-19. This article is based on previously conducted studies and does not contain any new studies with human participants or animals performed by the author.

\section{SYMPTOMS AND DEMOGRAPHICS}

Anosmia and ageusia previously considered pathognomonic of zinc deficiency $[1,2]$ are now also considered early symptoms of COVID19 , suggesting a shared mechanism.

Individuals age older than 65 , of male sex, and minority race or ethnicity are at high risk of contracting COVID-19 and once infected are at a higher risk of disease progression and death [3-6]. They are also at increased risk of developing hypertension and of progression to severe hypertension. These same groups also have been shown to have higher rates of ACE2 deficiency [7], suggesting that ACE2 deficiency plays a role in the response to COVID and in development of hypertension. Risk groups for COVID-19 and zinc deficiency largely overlap [8].

\section{CHRONIC CONDITIONS OF RISK FOR COVID-19}

The Centers for Disease Control and Prevention (CDC) has noted risk of severe COVID-19 
including rehospitalization in patients with any of five chronic conditions: chronic obstructive pulmonary disease (COPD), heart failure, diabetes with chronic complications, chronic kidney disease, and obesity [9]. Zinc deficiency has been implicated in COPD [10], heart failure [11], diabetes [12], and chronic kidney disease and obesity [13].

\section{SOCIOECONOMICS}

Patients at high risk of SARS-CoV-2 infection, disease progression, and death include racial and ethnic minorities [4]. These increased risks have been attributed to societal and racial inequities [14].

Baseline ACE2/zinc deficiency is hypothesized as a biochemical mediator of the socioeconomic conditions and diet to which high-risk individuals have been subject and also provides a logical mechanism as to how socioeconomic factors can impact individual risk.

\section{ACE2 AND RAS}

ACE and ACE2 are key components of the RAS providing homeostasis of blood pressure (BP) (Table 1). For details, see [15, Table 1] and [16].

ACE and ACE2 are homologous zinc metalloenzymes, each with an N-terminal signal sequence, a hydrophobic transmembrane section, and a cytoplasmic section [17]. Zinc is required to catalyze peptide hydrolysis [18; for ACE, prior to discovery of ACE2]. Activity of ACE is dependent on adequate dietary zinc. Adding zinc to the serum from zinc-deficient animals restored ACE activity and adding EDTA inhibited activity, reversible with zinc but not copper [19].

\section{VIRAL ENTRY}

SARS-CoV-2 utilizes epithelial cell ACE2 as a cellular entry receptor [7]. The viral spike glycoprotein $S$ binds to the host cell ACE2 receptor $[20,21]$. This is followed by release of the viral genome into the cell, accompanied by severe downregulation of the ACE2 receptor [7].

\section{ACE "ADVERSE" VS. ACE2 "PROTECTIVE" AXES OF RAS}

The major difference between ACE and ACE2 is the specificity of their carboxypeptidases-the ACE carboxypeptidase removes a single amino acid from inactive angiotensin (Ang) to yield active angiotensin II (Ang II). The carboxypeptidase of ACE2 removes two amino acids. The major substrate of ACE2 is Ang II; ACE2 degrades (active) Ang II to generate (vasodilatory) Ang 1-7 and Ang 1-9.

In normal functioning, the ACE positive feedback loop leads to amplification of Ang II and increased BP, inflammation, and

Table 1 Renin-angiotensin system overview

\begin{tabular}{|c|c|c|c|c|c|c|c|}
\hline Axis & $\begin{array}{l}\text { Adverse/ } \\
\text { protective }\end{array}$ & Substrate & Product & Feedback & Actions in RAS & Receptor & Downstream signal \\
\hline ACE & Adverse & $\begin{array}{c}\text { (Inactive) } \\
\text { Ang }\end{array}$ & $\begin{array}{c}\text { (Aactive) } \\
\text { Ang II }\end{array}$ & + & Amplifies & AT1 & $\begin{array}{l}\Uparrow \text { Vasoconstriction, } \\
\text { inflammation, } \\
\text { thromboses }\end{array}$ \\
\hline ACE2 & Protective & $\begin{array}{l}\text { (Active) } \\
\text { Ang II }\end{array}$ & $\begin{array}{c}\text { (Vasodilatory) } \\
\text { Ang 1-7 }\end{array}$ & - & $\begin{array}{l}\text { Modulates ACE, } \\
\text { fine control }\end{array}$ & Mas & $\begin{array}{l}\text { Mitigates pro- } \\
\text { inflammatory actions of } \\
\text { ACE }\end{array}$ \\
\hline
\end{tabular}

Ang angiotensin, Ang II angiotensin II, Ang 1-7 angiotensin 1-7 
thrombosis. The ACE2 negative feedback loop modulates the ACE loop, dampening the vasoactive, inflammatory, and thrombogenic actions of the ACE axis, regulating the RAS [22-24] providing homeostasis and smooth fine control, Table 1 (see also [15, Table 1]) and [7].

With zinc deficiency ACE2 activity is decreased which can lead to decrease of the "preventive" Ang 1-7 and Ang 1-9 and predominance of the ACE "adverse" Ang II. Upon SARS-CoV-2 infection, ACE2 is further decreased with viral cell entry, leading to loss of control.

Supplemental zinc could reverse this with preservation of the ACE2 axis, mitigation of the effects of the ACE axis with decreased inflammation, vasoconstriction, and thromboses [25].

\section{HYPOTHESIS: DEFICIENCIES OF ZINC AND ACE2, DYSREGULATION, AND THE TIPPING POINT}

Building on work of others [7, 17, 26] a hypothesis has emerged that deficiencies of ACE2 and zinc can explain the high-risk groups for COVID-19. Furthermore, clinical exacerbation that occurs in many high-risk patients at approximately day 8-9 (the beginning of the second week of illness) is thought to represent a "tipping point" with increasing oscillations, dysregulation, and disruption of the "Yin/Yang" balance [26] usually maintained by the RAS (Table 1). This loss of control and predominance of the ACE "adverse" axis [27] is signaled downstream by Ang II acting via the AT1 receptor to increase vasoconstriction, inflammation, and thromboses, In the lung, Ang II hyperactivity could result in multifocal pneumonia, acute respiratory distress syndrome (ARDS), thromboses, or (systemically) cytokine storm [7, 25, 27, 28].

Others [29] have stressed the cytokine actions with little mention of the failed RAS.

Loss of control in feedback systems occurs when perturbations or delays exceed the limits of the system [15].

\section{ZINC AND ACE2 DEFICIENCY IN PATIENTS WITH COVID-19}

In one series of hospitalized patients with COVID-19, 57.4\% were zinc deficient at the time of hospitalization compared to healthy controls [30]. Patients with COVID-19 who were zinc deficient at time of hospitalization were compared with those with normal zinc levels at hospitalization. Those showing zinc deficiency had increased complications (OR 5.54), ARDS $(18.5 \%$ vs. $0 \%, p=0.06)$, and mortality $(18.5 \%$ vs. $0 \%, p=0.06)$.

Verdecchia and colleagues [7] noted that the groups with higher rates of disease progression with COVID-19 (advanced age, male sex) have higher rates of ACE2 deficiency.

\section{TIME COURSE OF COVID-19: ACUTE EXACERBATION AND COMPLICATIONS}

Many patients with COVID-19 do relatively well in the first week after onset but then (especially high-risk patients) may experience an acute exacerbation, often with ARDS or other sequelae in the second week. Liu and colleagues [31] reviewed the clinical histories of 276 patients and selected 24 patients meeting predefined criteria of confirmed COVID-19 pneumonia. They noted clinical exacerbation (defined as moving from the general ward to the intensive care unit) at 8.8 days after disease onset. With exacerbation, patients had more clinical symptoms, and an increase in number of lung lobes involved, with multifocal lesions in 100\%. Complications seen in the second week of illness include multifocal pneumonia, ARDS, thromboses, or cytokine storm. Berlin et al. [32] have reviewed this "severe COVID-19" starting approximately 1 week after onset of illness.

Cantini et al. [33, Fig. 1] have diagrammed the time course of clinical symptoms and laboratory findings vs. viral load and immune response, showing an inflection at days 5-7 of illness. This inflection is the acute clinical exacerbation, the shift from the ACE2 protective axis to the ACE adverse axis with loss of the 
"Yin/Yang" balance as hypothesized above. The role of ACE2 and the shift to pro-inflammatory cytokines are highlighted [33, Fig. 2]. Goletti and Cantini [34] have added measures of severity and shown the relative pathogenesis of viral replication and immune response and stage of disease when different medications are active. Putting zinc supplementation onto this diagram would show most activity prior to symptom onset and early in infection before the day 7-8 inflection.

\section{TIME COURSE OF COVID-19 DISEASE: RIGHT DRUG AT THE RIGHT PHASE OF DISEASE}

Cantini and Goletti [33, 34] also raised an important concept regarding treatments for COVID-19: we have to use the right drug at the right phase of disease. Remdesivir and other antivirals are expected to be active early during active viral replication while dexamethasone or baricitinib act later dampening the SARS-CoV-2mediated immune response. Zinc supplementation for replenishment of zinc deficiency would be expected to be most beneficial if administered early, to maintain or replenish ACE2 and the ACE2 axis. Late administration, after the acute exacerbation of the "tipping point", would likely have diminished chance of success, as the pro-inflammatory Ang II "horse" would already be "out of the proverbial barn."

\section{KAWASAKI DISEASE AND MIS-C}

Late onset inflammatory disease resembling Kawasaki disease has been reported with COVID-19. Because it effects children older than usually seen with Kawasaki disease, it has now been renamed as multisystem inflammatory syndrome in children (MIS-C).

Decreased plasma zinc levels have been reported in children with Kawasaki disease [35]. This zinc deficiency resolved after treatment with intravenous immunoglobulins.

\section{COVID-19 LONG-TERM COMPLICATIONS}

The CDC has described a broad range of longterm complications seen in some patients continuing weeks to months post infection [36]. Complications include cardiovascular inflammation (see also Kawasaki disease, above), lung abnormalities, rash, hair loss, smell and taste problems. Several of these are reminiscent of symptoms of zinc deficiency (see below). Assessment of zinc status should be considered for patients with these long-term complications. Zinc supplementation for those found to be deficient may be of benefit.

\section{Zinc Deficiency}

Serum zinc levels of $84-159 \mu \mathrm{g} / \mathrm{dl}$ are generally considered the normal range; levels $60-83 \mu \mathrm{g} / \mathrm{dl}$ cover deficiency, physiological fluctuation, or drug-related variation; and levels below $59 \mu \mathrm{g} / \mathrm{dl}$ represent zinc deficient; and levels below $30 \mu \mathrm{g} /$ dl indicate definite deficiency [37]. Serum zinc levels are considered the most reliable means of diagnosing zinc deficiency [37]. However, as much of the total body zinc is protein bound or intracellular there may be situations with clinical manifestations of deficiency despite serum levels being at the lower end of normal [37].

Overt zinc deficiency is not common $[8,38]$; however, in a study of older adults ( $>60$ years old), 20-25\% had insufficient zinc intake [38]. Zinc intake may be insufficient, especially in the $2-4 \%$ of households that sometimes or often have a food shortage [38]. Foods rich in zinc include oysters and meats. Phytates found in some breads and cereals can bind zinc, thereby decreasing absorption. A US survey found reduced zinc levels in $2-3 \%$ of the population $[8,38]$. The Word Health Organization has estimated that $1 / 3$ of the world population may be zinc deficient [8].

Deficiency can also be seen associated with a variety of diseases or chronic conditions including some with poor intake or absorption (gastrointestinal surgery, ulcerative colitis, Crohn's disease, alcohol use, vegetarian diet) as well as others with increased loss via the 
gastrointestinal tract or kidneys [38]. Zinc deficiency can exacerbate renal disease and hypertension [37]. Estimates from nutritional surveys suggest that $20-25 \%$ of older individuals have inadequate zinc intake [39].

Antihypertensives (diuretics, ACE inhibitors, angiotensin 2 receptor blockers), beta blockers, and statins have been associated with zinc deficiency [40]. Zinc deficiency in hypertensives can be corrected with supplemental zinc.

Assessment of zinc status of an individual patient should thus take into account chronic conditions, dietary issues, and medications which may predispose to zinc deficiency [37].

White spots in the fingernails are sometimes seen with zinc deficiency [41].

\section{Excess Zinc}

Zinc excess also has its associated toxicities $[38,42]$. Zinc in doses as low as $60 \mathrm{mg} /$ day can antagonize intestinal absorption of copper resulting in anemia and neurological symptoms. Low dose copper has been added to some zinc supplements to prevent this [38]. Excess zinc supplementation $150-450 \mathrm{mg} /$ day has been associated with disruption of iron and immune function.

Zinc has been used to treat acne, the common cold (with mixed results), as a denture adhesive, for treatment of infant diarrhea, wound healing, and to delay progression of agerelated macular degeneration $[38,43]$. Excesses resulting in a US Food and Drug Administration warning have occurred with intranasal formulations for the common cold causing anosmia and zinc-containing denture adhesives.

\section{Zinc Supplementation}

The Food and Nutrition Board (FNB) of the Institute of Medicine of the National Academies has established recommended dietary allowances (RDAs) for zinc of $8 \mathrm{mg}$ for adult women and $11 \mathrm{mg}$ for adult men. They have also established tolerable upper intake levels (Uls) of $40 \mathrm{mg}$ for both adult women and men. These limits are not meant to apply to those receiving zinc for medicinal treatment while under observation.
Prolonged intake above the Uls has increased risk of adverse health effects [38]. Zinc replacement for zinc deficiency with $30 \mathrm{mg} /$ day zinc is generally considered safe. Zinc replacement is usually continued for 3-4 or sometimes to 6 months [37]. Response is better than 70\% if therapy is initiated soon after onset of zinc deficiency but is less in the elderly if treatment is delayed.

The AREDS studies for delaying progression of macular degeneration have provided longterm safety data on zinc supplementation; 3640 patients were randomized to (1) antioxidants plus zinc $80 \mathrm{mg} /$ day and copper daily $2 \mathrm{mg}$ /day, (2) zinc and copper without antioxidants, (3) antioxidants alone, and (4) inactive placebo. After the initial 5-year study participants were followed for an additional 5 years. Ten years after initial enrollment $70 \%$ of patients were taking zinc $80 \mathrm{mg} /$ day with copper $2 \mathrm{mg} /$ day for an average of 6.3 years. This exposure was associated with a statistically significant increased rate of genitourinary hospitalizations [44], most commonly for benign prostatic hyperplasia, urinary tract infection, urinary lithiasis, and renal failure. There were no prostate or other cancers with the zinc supplementation.

Optimal dosing and duration for treatment of zinc deficiency in COVID-19 has not been established; $30 \mathrm{mg} /$ day is considered safe while $80 \mathrm{mg} /$ day zinc with $2 \mathrm{mg} /$ day copper while monitoring for genitourinary events might be appropriate for clinical trials. Zinc $80 \mathrm{mg} /$ day with copper $2 \mathrm{mg} /$ day increased serum zinc by $17 \%$ in a year [45].

\section{NIH COVID-19 Treatment Guidelines, Zinc}

The National Institutes of Health (NIH) has published COVID-19 Treatment Guidelines including a section on zinc supplementation, last updated February 11, 2021 [46].

The panel reviewed available data from three studies: one randomized control study in severe patients [47] and two observational studies in PCR-confirmed [48] and SARS-CoV-2-infected hospitalized patients [49]. All three included zinc supplementation together with use of 
hydroxychloroquine (used as an ionophore). Only one [49] included an arm of zinc alone. The randomized controlled trial showed no benefit from combination. Frontera et al. [49] reported $24 \%$ reduction in in-hospital mortality with combination, but no benefit from zinc or hydroxychloroquine alone. The NIH COVID-19 Treatment Guidelines Panel recommendations were:

- There are insufficient data to recommend either for or against the use of zinc for the treatment of COVID-19.

- The COVID-19 Treatment Guidelines Panel (the Panel) recommended against using zinc supplementation above the recommended dietary allowance for the prevention of COVID-19, except in a clinical trial.

\section{RECENT STUDIES}

Arentz et al. [50] conducted a literature search of eight databases and four clinical trial registries yielding 1627 records of interest. They summarized that direct evidence of benefit of zinc for prevention or treatment of SARS-CoV-2 infection is not yet available; however, indirect evidence from the literature suggests that zinc supplementation may be useful to reduce the "risk, duration, and severity" of SARS-CoV-2 in older patients and those with chronic conditions known to be associated with zinc deficiency. They suggest that these high-risk individuals should have an assessment of zinc status as part of the COVID-19 clinical workup. Those found to have low or borderline zinc levels or those with evidence of insufficient intake or excess loss of zinc should be considered for zinc supplementation.

Thomas et al. [51] randomized 214 newly diagnosed ambulatory patients to open-label zinc (50 mg zinc gluconate daily), ascorbic acid, both, or neither for 10 days of treatment. There was no significant difference in the time to $50 \%$ decline in symptoms between the treatments and hospitalizations and deaths did not differ across the treatments. The 10-day duration of treatment may have been insufficient. The study was limited to ambulatory patients; this may have led inadvertently to underrepresentation of zinc-deficient patients most likely to benefit from zinc supplementation [52].

\section{PROPOSAL: RANDOMIZED CLINICAL TRIALS}

Randomized clinical trials (RCTs) are needed to confirm the benefit of zinc to decrease incidence and severity of COVID-19 in high-risk uninfected patients.

Assessment of zinc status in those with longterm complications of COVID-19 should also be considered. For both these groups, supplementation for those found to be zinc deficient may be beneficial.

The accumulating evidence above and the fact that zinc supplements are available, easy to use, well studied, and relatively safe suggests that randomized clinical trials for high-risk groups could be initiated now.

Zinc supplementation should not be a substitute for COVID-19 vaccination. However, zinc assessment and supplementation for those found to be zinc deficient may be of benefit for those unable or unwilling to access vaccination or those who may be at increased risk from viral variants that are insufficiently covered by currently available vaccines.

\section{LIMITATIONS}

This manuscript presents an internally consistent narrative to explain a number of observations of COVID-19, especially those occurring in high-risk patients. Most of the steps reflect clinical conditions described in the literature correlated to laboratory findings. Zinc serum levels may not reveal all deficiencies, and correlation does not guarantee causality. The optimal duration of zinc supplementation to replenish ACE2 in the setting of COVID has not been established. If supplementation longer than a week is required, initiation after COVID infection may be too late; zinc deficient patients at risk of COVID may have to be identified and zinc supplementation initiated prior to infection. Other models of pathophysiology of 
COVID-19 have been proposed [53]. What a consistent narrative can help us with is to guide us in design and implementation of randomized clinical studies. Hopefully new data will help clarify pathophysiological mechanisms and help us find new interventions to control this pandemic.

\section{CONCLUSIONS}

A growing body of evidence supports the premise that deficiencies of zinc and the zinc enzyme ACE2 are determinants of risk and severity of COVID-19. Focusing on the role of ACE2 in the RAS and in viral cell entry provides us a useful conceptual framework, revealing a cohesive and consistent narrative. Anosmia, demographics of high-risk groups, and the actions of the RAS point to deficiencies of zinc and ACE2 playing a role in COVID-19 exacerbation in high-risk individuals. In COVID-19 the baseline deficiency of ACE2 with further depletion due to the viral cell entry results in loss of control of the normal balance of the RAS and predominance of the ACE "adverse" axis. This in turn results in downstream increases in vasoconstriction, inflammation, and thromboses, leading to clinical sequelae of COVID-19 such as ARDs, thromboses, MIS-C, cytokine storm, etc.

RCTs are needed to confirm safety and efficacy of zinc supplementation to decrease incidence and severity of COVID-19 in high-risk patients.

Patients with clinical findings suggestive of zinc deficiency (poor diet, other risk factors [37]) should be considered for clinical and laboratory assessment and supplementation for those found to be zinc deficient. This may be of benefit especially for those unable or unwilling to access vaccination or those who may be at increased risk from viral variants that are insufficiently covered by currently available vaccines. If RCTs confirm the proposed benefit of zinc replacement therapy in high-risk zincdeficient patients, this would open a new window of attack to prevent the increased vasoconstriction, inflammation and thromboses seen in severe COVID.

\section{ACKNOWLEDGEMENTS}

Funding. No funding or sponsorship was received for this study or publication of this article. The Rapid Service Fee was funded by the author.

Authorship. All named authors meet the International Committee of Medical Journal Editors (ICMJE) criteria for authorship for this article, take responsibility for the integrity of the work as a whole, and have given their approval for this version to be published.

Disclosures. Miklos P. Salgo reports no relevant financial relationships.

Compliance with Ethics Guidelines. This article is based on previously conducted studies and does not contain any new studies with human participants or animals performed by the author.

Data Availability. Data sharing is not applicable to this article as no datasets were generated or analyzed during the current study.

Open Access. This article is licensed under a Creative Commons Attribution-NonCommercial 4.0 International License, which permits any non-commercial use, sharing, adaptation, distribution and reproduction in any medium or format, as long as you give appropriate credit to the original author(s) and the source, provide a link to the Creative Commons licence, and indicate if changes were made. The images or other third party material in this article are included in the article's Creative Commons licence, unless indicated otherwise in a credit line to the material. If material is not included in the article's Creative Commons licence and your intended use is not permitted by statutory regulation or exceeds the permitted use, you will need to obtain permission directly from the copyright holder. To view a copy of this licence, visit http://creativecommons.org/licenses/bync/4.0/. 


\section{REFERENCES}

1. Oster G, Salgo MP. Copper in mammalian reproduction. Adv Pharmacol Chemother. 1977;14: 327-409. 3589(08)60191-x.

2. National Institutes of Health Office of Dietary Supplements. Zinc: fact sheet for consumers. Updated July 15, 2020. https://ods.od.nih.gov/ factsheets/Zinc-Health\%20Professional/. Accessed 29 Sep 2020.

3. Conti S, Cassis P, Benigni A. Aging and the reninangiotensin system. Hypertension. 2012;60(4): 878-83. HYPERTENSIONAHA.110.155895.

4. Centers for Disease Control and Prevention. Coronavirus disease 2019 (COVID-19): COVID-19 hospitalization and death by race/ethnicity. Updated August 18, 2020. https://www.cdc.gov/ coronavirus/2019-ncov/covid-data/investigationsdiscovery/hospitalizationdeath-by-race-ethnicity. html. Accessed 29 Sep 2020.

5. Centers for Disease Control and Prevention. Coronavirus disease 2019 (COVID-19): older adults. Updated September 11, 2020. https://www.cdc.gov/ coronavirus/2019-ncov/need-extraprecautions/ older-adults.html. Accessed 29 Sep 2020.

6. Picheta R. Black people in the UK four times more likely to die from Covid19 than white people, new data shows. CNN. May 7, 2020. https://www.cnn. com/2020/05/07/uk/uk-coronavirusethnicitydeaths-ons-scli-gbr-intl/index.html. Accessed 29 Sep 2020.

7. Verdecchia P, Cavallini C, Spanevello A, Angeli F. The pivotal link between ACE2 deficiency and SARS-CoV-2 infection. Eur J Intern Med. 2020;76: 14-20. https://doi.org/10.1016/j.ejim.2020.04.037.

8. Wessels I, Rolles B, Rink L. The potential impact of zinc supplementation on COVID-19 pathogenesis. Front Immunol. 2020;11:1712. https://doi.org/10. 3389/fimmu.2020.01712.

9. Lavery AM, Preston LE, Ko JY, et al. Characteristics of of hospitalized COVID-19 patients discharged and experiencing same-hospital readmission-United States, March-August 2020. MMWR Morb Mortal Wkly Rep. 2020;69:1695-9. https://doi.org/ 10.15585/mmwr.mm6945e2.

10. Roscioli E, Jersmann HP, Lester S, et al. Zinc deficiency as a codeterminant for airway epithelial barrier dysfunction in an ex vivo model of COPD. Int J Chron Obstruct Pulmon Dis. 2017;12:3503-10. https://doi.org/10.2147/COPD.S149589.
11. Rosenblum H, Wessler JD, Gupta A, Maurer MS, Bikdeli B. Zinc deficiency and heart failure: a systematic review of the current literature. J Card Fail. 2020;26(2):180-9. https://doi.org/10.1016/j. cardfail.2020.01.005.

12. Farooq DM, Alamri AF, Alwhahabi BK, Metwally AM, Kareem KA. The status of zinc in type 2 diabetic patients and its association with glycemic control. J Family Community Med. 2020;27(1): 29-36. https://doi.org/10.4103/jfcm.JFCM_113_19.

13. Lobo JC, Torres JP, Fouque D, Mafra D. Zinc deficiency in chronic kidney disease: is there a relationship with adipose tissue and atherosclerosis? Biol Trace Elem Res. 2010;135(1-3):16-21. https:// doi.org/10.1007/s12011-009-8504-9.

14. Bouie J. Why coronavirus is killing African-Americans more than others. New York Times Sunday Review; 2020.

15. Salgo MP. Angiotensin-converting enzyme 2, feedback systems, and COVID-19. Consultant. 2020;61(4):e1-e11. https://doi.org/10.25270/con. 2020.10.00006.

16. Fountain JH, Lappin SL. Physiology, renin angiotensin system. StatPearls. Updated July 27, 2020. https://www.ncbi.nlm.nih.gov/books/NBK470410/. Accessed 29 Sept 2020.

17. Turner AJ, Hooper NM. Angiotensin-converting enzyme 2. In: Barrett AJ, Rawlings ND, Woessner JF, editors. Handbook of proteolytic enzymes, vol 1. 2nd ed. Amsterdam: Elsevier; 2004. p. 349-51. https://doi.org/10.1016/B978-0-12-079611-3. 50092-6.

18. Būnning P, Riordan JF. The functional role of zinc in angiotensin converting enzyme: implications for the enzyme mechanics. J Inorg Biochem. 1985;24(3):183-98. https://doi.org/10.1016/01620134(85)85002-9.

19. Reeves PG, O'Delll BL. Effect of dietary zinc deprivation on the activity of angiotensin-converting enzyme in serum of rats and guinea pigs. J Nutr. 1986;116(1):128-34. https://doi.org/10.1093/jn/ 116.1.128.

20. Fang L, Karakiulakis G, Roth M. Are patients with hypertension and diabetes mellitus at increased risk for COVID-19 infection? Lancet Respir Med. 2020;8(4): e21. https://doi.org/10.1016/S22132600(20)30116-8.

21. Baden LR, Rubin EJ. Covid-19: the search for effective therapy. N Engl J Med. 2020;382(19):1851-2. https://doi.org/10.1056/NEJMe2005477. 
22. Patel VB, Zhong JC, Grant MB, Oudit GY. Role of the ACE2/angiotensin 1-7 axis of the renin-angiotensin system in heart failure. Circ Res. 2016;118(8):1313-26. https://doi.org/10.1161/ CIRCRESAHA.116.307708.

23. Kuba K, Imai Y, Penninger JM. Multiple functions of angiotensin-converting enzyme 2 and its relevance in cardiovascular disease. Circ J. 2013;77(2): 301-8. https://doi.org/10.1253/circj.CJ-12-154.

24. Turner JT. ACE2 cell biology, regulation, and physiological functions. In: Unger T, Steckelings UM, dos Santos RAS, editors. The protective arm of the renin angiotensin system: functional aspects and therapeutic implications. London: Academic; 2015. p. 185-9. https://doi.org/10.1016/B978-0-12801364-9.00025-0.

25. Oyagbemi AA, Ajibade TO, Aboua YG, et al. Potential health benefits of zinc supplementation for the management of COVID-19 pandemic. J Food Biochem. 2021;00: e13604. https://doi.org/ 10.1111/jfbc. 13604 .

26. Zamai L. The yin and yang of ACE/ACE2 pathways: the rationale for the use of renin-angiotensin system inhibitors in COVID-19 patients. Cells. 2020;9(7):E1704. https://doi.org/10.3390/ cells9071704.

27. Thomas MC, Tikellis C. Losing control: positive and negative feedback in the renin angiotensin system. Curr Hypertens Rev. 2009;5(3):222-6. https://doi. org/10.2174/157340209788921194.

28. Fajgenbaum DC, June CH. Cytokine storm. N Engl J Med. 2020;383:2255-73. https://doi.org/10.1056/ NEJMra2026131.

29. Goldin CJ, Vázquez R, Polack FP, Alvarez-Paggi D. Identifying pathophysiological bases of disease in COVID-19. Transl Med Commun. 2020;5:15. https://doi.org/10.1186/s41231-020-00067-w.

30. Jothimani D, Kailasam E, Danielraj S, et al. COVID19: poor outcomes in patients with zinc deficiency. Int J Infect Dis. 2020;100:343-9. https://doi.org/10. 1016/j.ijid.2020.09.014.

31. Liu J, Chen T, Yang H, et al. Clinical and radiological changes of hospitalised patients with COVID19 pneumonia from disease onset to acute exacerbation: a multicentre paired cohort study. Eur Radiol. 2020. https://doi.org/10.1007/s00330-02006916-4.

32. Berlin DA, Gulick RM, Martinez FJ. Severe Covid-19. N Engl J Med. 2020;383:2451-60. https://doi.org/ 10.1056/NEJMcp2009575.
33. Cantini F, Goletti D, Petrone L, et al. Immune therapy, antiviral therapy, or both for COVID-19. Drugs. 2020;80:11929-46.

34. Goletti D, Cantini F. Baricitinib therapy in COVID19 pneumonia: an unmet need fulfilled. N Engl J Med. 2021;384:9.

35. Lebranchu Y, Malvy D, Richard MJ, et al. Kawasaki disease and oxidative metabolism. Clin Chim Acta. 1990;187(3):193-8. https://doi.org/10.1016/00098981(90)90104-Z.

36. Centers for Disease Control and Prevention. COVID-19, long-term effects of COVID-19. 2021. https://www.cdc.gov/coronavirus/2019-ncov/longterm-effects.html. Assessed 28 Feb 2021.

37. Yanagisawa H. Zinc deficiency and clinical practice. JMAJ. 2004;47(8):359-64.

38. National Institute of Health. Zinc fact sheet for health professionals. 2021. https://ods.od.nih.gov/ factsheets/Zinc-HealthProfessional/. Accessed 20 Feb 2021.

39. Ervin RB, Kennedy-Stephenson J. Mineral intakes of elderly adult supplement and non-supplement users in the third national health and nutrition examination survey. J Nutr. 2002;132:3422-7. https://doi.org/10.1093/jn/132.11.3422.

40. Mossink JP. Zinc as nutritional intervention and prevention measure for COVID-19 disease. BMJ Nutr Prev Health. 2020;3: e000095. https://doi.org/ 10.1136/bmjnph-2020-000095.

41. Pfeiffer CC, Jenney EH. Fingernail white spots: possible zinc deficiency. JAMA. 1974;228(2):157. https://doi.org/10.1001/jama.1974. 03230270017005.

42. Igic PG, Lee E, Harber W, Roach KW. Toxic effects associated with consumption of zinc. Mayo Clin Proc. 2002;77:713-6.

43. National Institutes of Health, National Eye Institute. AREDS/AREDS2 Clinical Trials. 2021. https:// www.nei.nih.gov/research/clinical-trials/agerelated-eye-disease-studies-aredsareds2/aboutareds-and-areds2. Accessed 20 Feb 2021.

44. Johnson AR, Munoz A, Gottlieb JL, Jarrard DF. High dose zinc increases hospital admissions due to genitourinary complications. J Ufol. 2007;177: 638-43.

45. McPherson SW, Keunen JE, Bird AC, et al. Investigate oral zinc as a prophylactic treatment for those at risk of CoVID-19. Amer J Ophthalmol. 2021. https://doi.org/10.1016/ajo.2020.04.028. 
46. COVID-19 Treatment Guidelines Panel. Coronavirus Disease 2019 (COVID-19) Treatment Guidelines, Zinc Supplementation and COVID-19, National Institutes of Health. 2021. https://www. covid19treatmentguidelines.nih.gov/supplements/ zinc. Accessed 14 Feb 2021.

47. Abd-Elsalam S, Soliman S, Esmail ES, et al. Do zinc supplements enhance the clinical efficacy of hydroxychloroquine?: a randomized, multicenter trial. Biol Trace Elem Res. 2020. https://doi.org/10. 1007/s12011-020-02512-1.

48. Yao JS, Paguio JA, Dee EC, et al. The minimal effect of zinc on the survival of hospitalized patients with COVID-19: an observational study. Chest. 2020;159:108-11.

49. Frontera JA, Rahimian JO, Yaghi S, et al. Treatment with zinc is associated with reduced in-hospital mortality among COVID-19 patients: a multi-center cohort study. Res Sq. 2020. https://doi.org/10. 21203/rs.3.rs-94509/v1.
50. Arentz S, Hunter J, Yang G, et al. Zinc for the prevention and treatment of SARS-CoV-2 and other acute viral respiratory infections a rapid review. Adv Integr Med. 2020;7(4):252-60. https://doi.org/10. 1016/j.aimed.2020.07.009.

51. Thomas S, Patel D, Bittel B, et al. Effect of high-dose zinc and ascorbic acid supplementation vs usual care on symptom length and reduction among ambulatory patients with SARS-CoV-2 infection: the COVID A to $\mathrm{Z}$ randomized clinical trial. JAMA Netw Open. 2021;4(2):e210369. https://doi.org/10. 1001/jamanetworkopen.2021.0369 (ClinicalTrials.govIdentifier:NCT04342728).

52. Salgo M. Study population selection likely excluded high-risk patients most likely to benefit. JAMA Netw Open. 2021;87:570-4.

53. Bohn MK, Hall A, Sepiashvili L, et al. Pathophysiology of COVID-19: mechanisms underlying disease severity and progression. Physiology. 2020;35(5):288-301. https://doi.org/10.1152/ physiol.00019.2020. 